\title{
PRESERVANDO CECROPIAIS NATIVOS EM PAISAGENS AMAZÔNICAS: UMA ESTRATÉGIA ECOLÓGICA PARA SOLOS DEFICIENTES POR FÓSFORO
}

\section{Patrícia Chaves de Oliveira}

Professora Adjunta III UFOPA; Engenheira Agrônoma pela UFRA- PA, Mestra em

Fisiologia de Plantas pela UFLA- MG e Doutora em Ciências Agrárias pela UFRA.

Atualmente coordena o Laboratório de Estudos de Ecossistemas Amazônicos LEEA, da UFOPA onde atua em ecofisiologia de ambientes amazônicos, ecopedagogia, agroecologia e extensão rural.pchaves@ufpa.br

\section{Lício Mota}

Bolsista ITI-CNPQ, Licenciando em Biologia- UFOPA

\section{RESUMO}

Os Cecropiais nativos formados pela espécie Cecropiapalmata, dentre outras, a qual é acumuladora de fósforo (P) em tecidos foliares e cascas podem prestar um serviço ecológico em paisagens amazônicas com deficiência por fósforo. Os objetivos desta pesquisa foram a observação da translocação do fósforo em folhas ontogeneticamente diferentes de Cecropiapalmata, bem como, a análise da dinâmica do fósforo em solos sob conglomerados de Cecropiapalmata. Os teores de fósforo (P) em tecidos foliares de Cecropiapalmata demonstraram valores elevados, em torno de $8,4 \mathrm{mg} / \mathrm{kg}$ em folhas novas e $5,6 \mathrm{mg} / \mathrm{kg}$ em folhas com maturação fisiológica, sugerindo serrapilheira de alta qualidade para o ambiente. Além disso, os solos sob influência da rizosfera desta espécie apresentaram importantes hot spots de fósforo.

PALAVRAS-CHAVE: Amazônia, Cecropia, fósforo, solos, conservação

\section{PRESERVING NATIVE CECROPIALS IN AMAZONIAN LANDSCAPES: AN ECOLOGICAL STRATEGY IN DEFICIENT SOIL FOR PHOSPHORUS.}

\begin{abstract}
The conservation of species for ecological services in Amazonian landscapes as local agro-ecosystems of Low Amazon is of extreme importance in input of minerals through the litter produced for these species. The native cecropials, formed for the Cecropiapalmata, amongst others, which are accumulative of phosphorus $(\mathrm{P})$ in leaf tissues, can give an ecological service in Amazonian landscapes with deficiency for P. The objective of this research was understanding the translocation of phosphorus in different ontogenetically leaves of Cecropiapalmata; as well as, the analysis of the dynamics of $\mathrm{P}$ in soil under conglomerates of Cecropiapalmata. The $\mathrm{P}$ concentrations in leaf tissues of Cecropiapalmatahad demonstrated high values, around $8.4 \mathrm{mg} / \mathrm{kg}$ on new leaves and 5.6 $\mathrm{mg} / \mathrm{kg}$ on leaves with physiological maturation, suggesting high quality of litter for the environment. Moreover, the soil under influence of the rizosphere of this important species had presented hotspots of phosphorus.
\end{abstract}

KEY-WORDS: Amazon, Cecropia, phosphorus, soil, conservation. 


\section{PRESERVANDO CECROPIAIS NATIVOS EM PAISAGENS AMAZÔNICAS: UMA ESTRATÉGIA ECOLÓGICA EM SOLOS DEFICIENTES POR FÓSFORO.}

\section{INTRODUÇÃO}

Aconservação de espécies prestadoras de serviços ecológicosem paisagens amazônicas comoos agroecossistemas locais do Baixo Amazonas é de extrema importância no input de minerais através da serrapilheira produzida por estas espécies. Os Cecropiais nativos, formados pela espécie Cecropiapalmata, dentre outras, a qual é acumuladora de fósforo (P) em tecidos foliares e cascas (Oliveira, 2005) podem prestar um serviço ecológico em paisagens amazônicas com baixos teores de fósforo.

A serrapilheiraé constituída de restos vegetais e, ou animais em diferentes estágios de decomposição formando uma cobertura sobre o solo produzida por essa espécie, uma vez rica em fósforo orgânico e mantendo-se nos sistemas de produção pode vir a promover o aumento da disponibilidade desse nutriente às culturas agrícolas locais.

De acordo com Campos etal (2008) estudando o acúmulo de serrapilheira em fragmentos de mata mesofítica e em cerrado stricto senso encontrou uma relação muito forte entre a produção de serrapilheira e a sazonalidade, e portanto com as condições de radiação, luz e umidade. Sendo assim, em ecossistemas amazonicos, onde a sazonalidade é fortemente marcada pela flutuação nas precipitações pluviométricas, é de se esperar também um efeito semelhante na produção de serrapilheira.

Contudo, outros fatores também influenciam a qualidade da serrapilheira. Segundo Rigobelo et al (2004) em solos sob plantios de Eucalypthus e Pinus foi observada uma correlação positiva entre matéria orgânica do solo, concentração de $\mathrm{CO}_{2} \mathrm{com}$ a quantidade de bactéria total, respiração e atividade das desidrogenases. Dessa forma, a serrapilheira de Cecropiapalmata também poderia estar sendo influenciada por atividades microbianas em solos amazonicos.

A forma de dispersão da espécie Cecropiapalmata por ser em conglomerados nas vegetações secundárias, denominadas de capoeiras, delineia pontos bem localizados com maior fertilidade do que áreas mais distantes destes Cecropiais em função da concentração de fósforo ser mais elevada nestes locais. A conservação desses conglomerados (Cecropiais) nos agroecossistemas estudados do Território do Baixo Amazonas pode favorecer a retenção deste mineral que é limitante nos latossolos da região.

Diante destes aspectos, essa pesquisa teve como principal objetivo preservar os Cecropiais nativos em áreas de agricultura familiar na Amazônia que seriam tradicionalmente queimadas para plantios agrícolas. Os objetivos específicos se referiram à:

1. Observação da translocação do fósforo em folhas novas, maduras e senescentes de $C$. palmata; 2. Análise da dinâmica do fósforo em solos sob conglomerados de Cecropiapalmata.

\section{METODOLOGIA}

A pesquisa foi desenvolvida no município de Santarém, na meso-região do Baixo Amazonas em florestas secundárias localmente denominadas de capoeiras no contexto da agricultura 
familiar. O clima é classificado como Ami no sistema Köpen, com uma temperatura média anual de $25^{\circ} \mathrm{C}$ e umidade relativa de $86 \%$. A precipitação pluvial anual média é de 2000 $\mathrm{mm}$, podendo variar entre 600 e $3000 \mathrm{~mm}$ anuais. Os maiores índices pluviométricos são registrados entre os meses de fevereiro e maio. A estação seca é curta e dura de dois a quatro meses, geralmente entre os meses de agosto a novembro, período no qual a precipitação pode chegar a $60 \mathrm{~mm} / \mathrm{mês}$ (Hernandes et al., 1993 e Silva, 1989). O solo (latossolo amarelo, EMBRAPA, 2006) da área de estudo apresentava a seguinte granulometria: $43 \%$ de areia, $32 \%$ de argila e $25 \%$ de silte (Ribeiro, 2007). A vegetação da área estudada caracterizava-se como uma composição florística de 44 famílias e 75 espécies (Ferreira, 2007), sendo que dentre elas estava a espécie Cecropiapalmata.

O experimento foi desenvolvido numa área de agricultura familiar no Assentamento Rural Coletivo do Eixo Forte cujo referenciamento foi $2^{\circ} 29^{\prime} 781^{\prime \prime S}$ e $54^{\circ} 50^{\prime}$ 299”W. Nesta propriedade foi selecionado um Cecropial com 15 árvores de Cecropiapalmataonde então foram coletadas amostras de solo e tecidos foliares para determinação das concentrações de fósforo (P).

As coletas de solo para a análise de fósforo foram feitas com um trado modelo Sonda Terra em duas profundidades; 0 a $10 \mathrm{~cm}$ e 10 a $20 \mathrm{~cm}$ em três pontos definidos, sendo que o primeiro ponto foi naregião próxima a base do Cecropial; o segundo a 5 metros e o terceiro a 10 metros, com cinco repetições para cada profundidade em cada uma das distâncias, totalizando 30 amostras. Cada amostra de solo foi acondicionadaem sacos plásticos com as devidas identificações e levadas ao laboratório de Ecofisiologia Vegetal da UFPA para secagem 'à uma temperatura de $60^{\circ} \mathrm{C}$ e realização de análises químicas.

A coleta de folhas foi realizada manualmente, sendo 10 folhas (repetições) para cada estágio foliar: novas, maduras e velhas. Tais amostras foram levadas para estufa no laboratório da UFOPA onde permaneceram por 72 horas a uma temperatura de $60^{\circ} \mathrm{C}$. Posteriormente foram moídas em moinho de liteira e raízes, modelo MA 340 para em seguida serem realizadas as determinações de acordo com a metodologia de Júlio Costa 2004, dos teores de fósforo.

As análises estatísticas foram realizadas pelo programa BIOESTAT 4.0 e se caracterizavam por Análises Multivariadas através dos testes de Hotteling e análise de Componentes Principais.

\section{RESULTADOS E DISCUSSÕES}

Os teores de fósforo $(\mathrm{P})$ em tecidos foliares de Cecropiapalmata demonstraram valores elevados, 8,4 e 5,6 $\mathrm{mg} \mathrm{kg}^{-1}$ nas folhas novas e maduras, respectivamente, conforme Quadro 1. Estes resultados estão de acordo com a literatura (Oliveira, 2005) e sugerem a eficiência no acúmulo de fósforo que essa espécie desenvolve em ambientes com déficit deste mineral como no cecropial estudado. Tal eficiência pode estar relacionada à atividade de enzimas como a fosfatase ácida, que uma vez exsudada em altas concentrações pelo sistema radicular aumenta a disponibilidade de fósforo orgânico nos solos. Os maiores desvios padrões e coeficientes de variação para os teores de fósforo foram observados nas folhas novas de acordo com o Quadro 1, indicando que as folhas mais velhas apresentam certa estabilidade no teor de fósforo orgânico. 
Quadro 1- Estatística Descritiva quanto ao teor de fósforo (P) em $\mathrm{mg} / \mathrm{kg}$ em folhas de Cecropiapalmata sob diferentes estádios ontogenéticos, folha nova (fn), folha madura (fm) e folha senescente (fs).

\begin{tabular}{|l|l|l|l|}
\hline Fósforo foliar (mg/kg) & Fn & Fm & Fs \\
\hline Mínimo & 6.000 & 5.000 & 0 \\
\hline Máximo & 10.000 & 7.000 & 0 \\
\hline Amplitude & 4.000 & 2.000 & 0 \\
\hline Média aritmética & 8.400 & 5.600 & 0 \\
\hline Coeficiente de Variação & $19.92 \%$ & $15.97 \%$ & --- \\
\hline
\end{tabular}

A diferença entre as médias dos teores de fósforo em folhas novas, maduras e senescentes de Cecropiapalmata foram diferentes significativamente $(\mathrm{p}<0.001)$ conforme dados contidos no Quadro 2 A redução destes valores até os níveis muito baixos nas folhas senescentes sugere que o fósforo é praticamente todo reabsorvido antes que as folhas sofram abscisão e se desloquem para o solo. Este cenário indica uma estratégia de economia de fósforo por Cecropiais nativos em ambientes com estresse como os solos amazônicos. Estes resultados sugerem ainda que tecidos foliares de Cecropiapalmata possam ser utilizados como cobertura morta do solo ou na fabricação de tortas ricas em fósforo como adubação orgânica para as culturas agrícolas, o que caracterizaria uma prática agroecológica importante na região, haja vista, a abundância desta espécie nos ambientes de agricultura familiar em Assentamentos Rurais.

Quadro 2 - Análise de Variância dos teores de fósforo (P) em $\mathrm{mg} / \mathrm{kg}$ em tecidos foliares de Cecropiapalmata sob diferentes estádios ontogenéticos, folha nova (fn), folha madura (fm) e folha senescente (fs).

\begin{tabular}{|l|l|l|l|}
\hline Causas de variação & GL & SQ & QM \\
\hline Tratamentos & 2 & 182,933 & 91,467 \\
\hline (p) probabilidade $=$ & $<0.0001$ & & \\
\hline Media 1 (folha nova) $=$ & 8,400 & & \\
\hline Media 2 (folhamadura) $=$ & 5.600 & & \\
\hline Media 3 (folhasenescente) & 0.000 & & \\
\hline & & & \\
\hline Tukey: & Diferença & Q & $(p)$ \\
\hline Media ( 1 a 2) & 2,800 & 5,715 & $<0.01$ \\
\hline Media (1 a 3) $=$ & 8,400 & 17,146 & $<0.01$ \\
\hline Media ( 2 a 3) & 5,600 & 11,431 & $<0.01$ \\
\hline
\end{tabular}

O solo sob influência da rizosfera do Cecropial estudado não demonstrou diferenças significativas $(\mathrm{p}=0,44)$ quanto aos teores de fósforo entre as duas profundidades estudadas (10 e $20 \mathrm{~cm}$ ), nem tão pouco quanto a distância do Cecropial(0, 5 e $10 \mathrm{~m}$ ) conforme mostraram os resultados do Teste de Hotteling (Quadro 3). Embora uma leve tendência tenha sido observada para os maiores valores $(2,0-3,2 \mathrm{mg} / \mathrm{kg})$ de fósforo nos pontos 
próximos ao Cecropial (0 e $5 \mathrm{~m}$ ). Estes dados sinalizam que os altos valores de fósforo nos solos encontrados próximos ao Cecropial se caracterizam perse importante sítios para o consorcio de culturas agrícolas, pois normalmente os teores de fósforo reduzem à medida que nos distanciamos dos Cecropiais. Sendo assim, o serviço ecológico que esta espécie propicia aos agroecossistemas do Baixo Amazonas e de extrema importância no input mineral dos ciclos biogeoquímicos locais e conseqüentemente na sustentabilidade destes ecossistemas produtivos.

Quadro 3-Resultados do teste de Hotteling para comparação dos teores de fósforo (P) em mg/kg em solos sob duas profundidades (0-10cm, Amostra 1; 10-20cm Amostra 2) e à três distâncias $(0,5$ e $10 \mathrm{~m})$ do conglomerado das árvores de Cecropiapalmataem área de agricultura familiar no Assentamento Rural Coletivo do Eixo Forte.

\begin{tabular}{|l|l|l|l|}
\hline & Var 1=P solo -0 & Var 2=P solo -5 & Var 3=P solo 10 \\
\hline Amostra 1: 10 cm média $=$ & 3.200 & 3.600 & 2.000 \\
\hline Amostra 2: 20 cm média $=$ & 2.800 & 1.868 & 2.088 \\
\hline T2 (Hotteling) $=$ & 4.109 & --- & --- \\
\hline (p) $=$ & 0.444 & --- & --- \\
\hline
\end{tabular}

A Análise de Componentes Principais entre os teores de fósforo em folhas novas, maduras e senescentes demonstrou que o compartimento folha nova e madura explica a maior parte da variação, $67,18 \%$ e $29,20 \%$ respectivamente; o que indica que estes estágios ontogenéticos foliares são os melhores bioindicadores para se compreender a translocação do fósforo em folhas de espécie potencialmente acumuladora de fósforo como Cecropiapalmataconforme Quadro 4 e Figura 1.

Quadro 4- Resultados da Análise de Componentes Principais entre os teores de fósforo

(P) em mg/kg nos tecidos foliares de Cecropiapalmata sob diferentes estádios ontogenéticos, folha nova (fn), folha madura (fm) e folha senescente (fs).

\begin{tabular}{|l|l|l|l|l|}
\hline $\begin{array}{c}\text { Matriz de } \\
\text { Correlação }\end{array}$ & Coluna 1=P fn & Coluna 2=Pfm & Coluna 3=Pfs & \\
\hline Coluna 1=Pfn & 1.0000 & --- & --- & --- \\
\hline Coluna 2= Pfm & $-0,5345$ & 1.0000 & --- & --- \\
\hline Coluna 3= Pfs & 0,7857 & $-0,1336$ & 1.0000 & --- \\
\hline & Autovalores & $\%$ total da variância & Autovaloracumulado & $\%$ acumu \\
\hline Componente 1 = Pfn & 2.0156 & $67.1866 \%$ & 2.0156 & $67.1866 \%$ \\
\hline Componente 2 = Pm & 0,876 & $29.2016 \%$ & 2.8916 & $96.3882 \%$ \\
\hline Componente 3 = Ps & 0,1084 & $3.6118 \%$ & 3.0000 & $100 \%$ \\
\hline
\end{tabular}




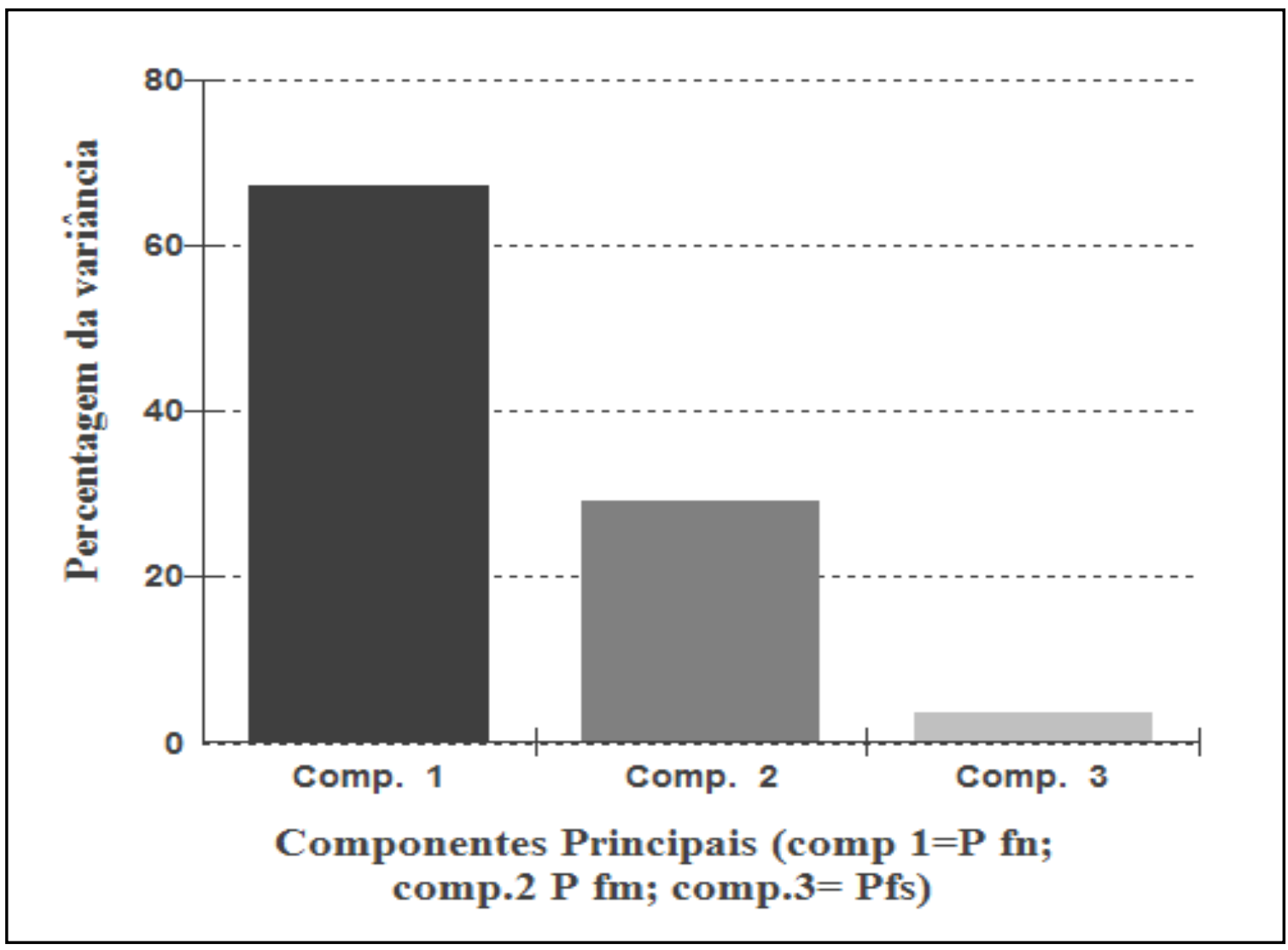

Figura 1-Resultados da Análise de Componentes Principais (comp.1= teor de $\mathbf{P}$ em folhas novas; comp. $2=$ teor de $P$ em folhas maduras; comp. $3=$ teor $\mathbf{d e} P$ em folhas senescentes) em mg/kg em tecidos de Cecropiapalmata.

Quando a mesma análise de Componentes Principais se aplica sobre os teores de fósforo nas diferentes profundidades de solo e sob distintas distâncias da reboleira do Cecropial, os resultados demonstraram que os melhores parâmetros, ou seja, os componentes principais ou bioindicadores do status do fósforo em rizosfera de espécies potencialmente acumuladoras de fósforo seriam a distância de $5 \mathrm{~m}$ e profundidade de $10 \mathrm{~cm}(5 \mathrm{~m} / 10 \mathrm{~cm})$, seguida da distância de $0 \mathrm{~m}$ e profundidade de $10 \mathrm{~cm}(0 \mathrm{~m} / 10 \mathrm{~cm})$ e por último a distância de $0 \mathrm{~m}$ e $20 \mathrm{~cm}$ de profundidade $(0 \mathrm{~m} / 20 \mathrm{~cm})$, as quais explicaram 53,27\%, 26,58\% e 13,88\% da variação total respectivamente, conformeQuadro 5 e Figura 2. Estes dados sugerem, portanto, espaços com altos teores de fósforo para futuros plantios em consórcio com o intuito de aproveitar este mineral disponível próximo aos Cecropiais nativos em áreas de agricultura familiar nos Assentamentos Rurais. Nota-se a importância em se conservar Cecropiais nativos, a fim de manter hotspotsde fósforo em paisagens Amazônicas, potencializando o uso do fósforo de forma agro-ecológica nestes modelos de agricultura. 
Quadro 5- Análise de Componentes Principais entre os teores de fósforo (P) em mg/kg em solos sob duas profundidades $(0-10 \mathrm{~cm}$ e $10-20 \mathrm{~cm})$ e à três distâncias $(0,5$ e $10 \mathrm{~m})$ da reboleira das árvores de Cecropiapalmataem área de agricultura familiar no Assentamento Rural Coletivo do Eixo Forte.

\begin{tabular}{|c|c|c|c|c|c|c|}
\hline $\begin{array}{l}\text { Matriz de } \\
\text { Correlação }\end{array}$ & $\begin{array}{l}\text { P solo } \\
5 \mathrm{~m} / 10 \mathrm{c} \\
\mathrm{m}\end{array}$ & $\begin{array}{l}\text { P solo } \\
0 \mathrm{~m} / 10 \mathrm{~cm}\end{array}$ & $\begin{array}{l}\text { P solo } \\
\text { Om/ 20c } \\
\mathrm{m}\end{array}$ & $\begin{array}{l}\text { P solo } \\
10 \mathrm{~m} / 20 \mathrm{~cm}\end{array}$ & $\begin{array}{l}\text { P solo } \\
10 \mathrm{~m} / 1 \\
0 \mathrm{~cm}\end{array}$ & $\begin{array}{l}\text { P solo } \\
5 \mathrm{~m} / 20 \mathrm{~m}\end{array}$ \\
\hline $\begin{array}{l}\text { Coluna } 1=\text { Pso } \\
5 / 10\end{array}$ & 1.000 & --- & --- & --- & --- & --- \\
\hline $\begin{array}{l}\text { Coluna 2= Pso } \\
0 / 10\end{array}$ & 0,619 & 1.000 & --- & --- & --- & --- \\
\hline $\begin{array}{l}\text { Coluna } 3=\text { Pso } \\
0 / 20\end{array}$ & $-0,298$ & $-0,171$ & 1.000 & --- & --- & --- \\
\hline Coluna $4=10 \mathrm{~m} / 20$ & $-0,111$ & $-0,266$ & $-0,321$ & 1.000 & --- & --- \\
\hline Coluna $5=10 \mathrm{~m} / 10$ & $-0,583$ & $-0,645$ & 0,851 & 0.000 & 1.0000 & --- \\
\hline \multirow[t]{3}{*}{ Coluna $6=5 \mathrm{~m} / 20$} & 0,921 & 0,763 & $-0,024$ & $-0,120$ & $-0,4226$ & 1.0000 \\
\hline & --- & --- & --- & --- & --- & --- \\
\hline & $\begin{array}{l}\text { Autovalo } \\
\text { res }\end{array}$ & $\begin{array}{l}\text { \%totaldavari } \\
\text { ância }\end{array}$ & Autovalor & $\begin{array}{l}\% \\
\text { acumulada }\end{array}$ & --- & --- \\
\hline $\begin{array}{l}\text { Comp. } 1 \text { = P so } \\
5 \mathrm{~m} / 10 \mathrm{~cm} \\
\text { profundid. }\end{array}$ & 31,966 & $53.277 \%$ & 31,966 & $53.277 \%$ & --- & --- \\
\hline $\begin{array}{l}\text { Compo. } 2 \text { = P so } \\
0 \mathrm{~m} / 10 \mathrm{~cm}\end{array}$ & 15,949 & $26.581 \%$ & 47,915 & $79.858 \%$ & --- & --- \\
\hline $\begin{array}{l}\text { Compo. } 3=\text { Pso } \\
\text { Om/20cm }\end{array}$ & 0,833 & $13.886 \%$ & 56,247 & $93.745 \%$ & --- & --- \\
\hline $\begin{array}{l}\text { Compo.4 = Pso } \\
10 / 20\end{array}$ & 0,375 & $6.254 \%$ & 60,000 & $100 \%$ & --- & --- \\
\hline $\begin{array}{l}\text { Compo.5 = Pso } \\
10 / 10\end{array}$ & 0.000 & $0,000 \%$ & 60,000 & $100 \%$ & --- & --- \\
\hline
\end{tabular}

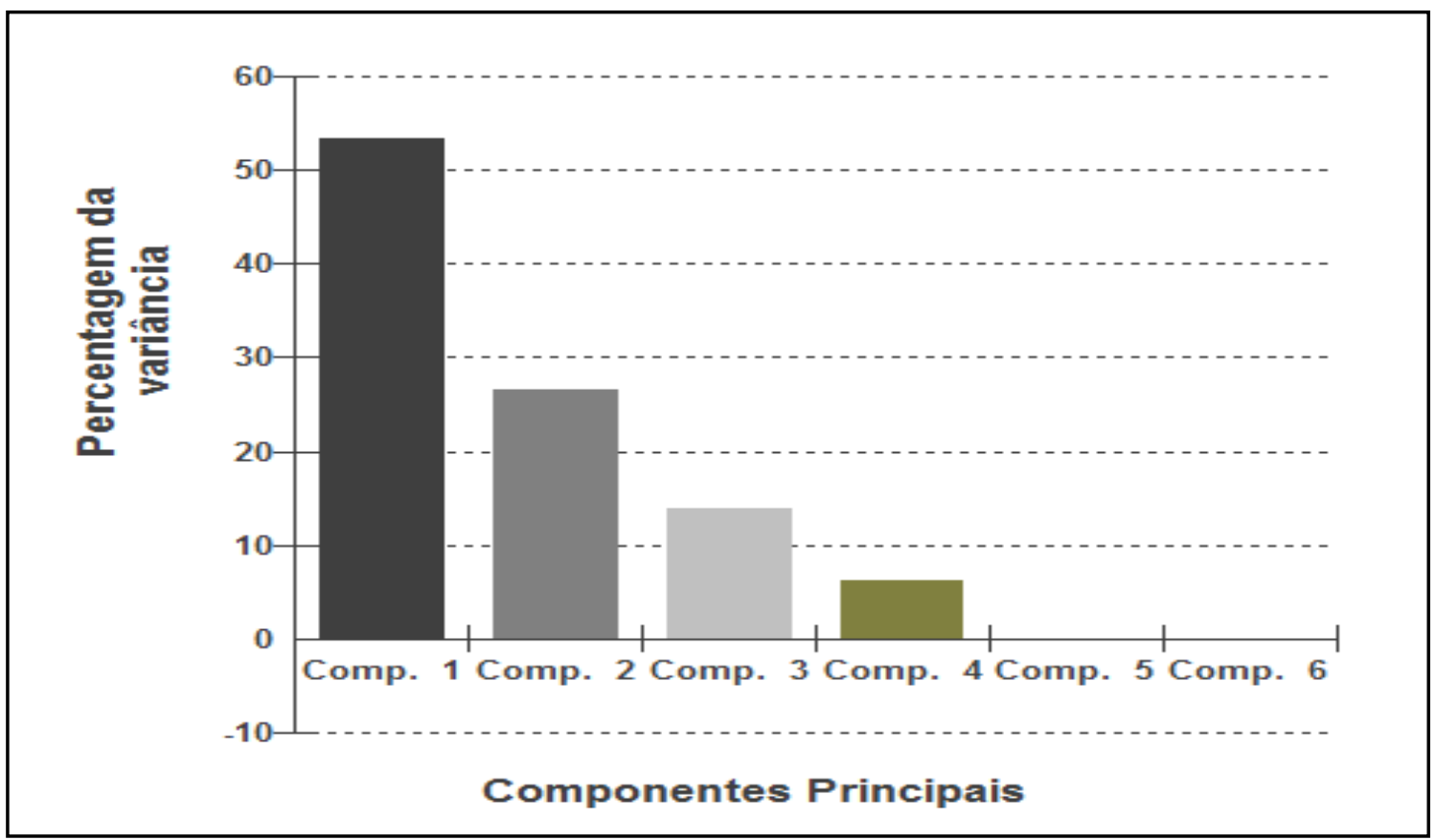

Figura2- Resultados da Análise de Componentes Principais (comp.1= P solo à $5 \mathrm{~m}$ e 10 cm de profundidade; comp. $2=P$ solo $0 \mathrm{~m} / 10 \mathrm{~cm}$; comp. $3=P$ solo $0 \mathrm{~m} / 20 \mathrm{~cm}$; comp.4= $P$ solo $10 \mathrm{~m} / 20 \mathrm{~cm}$; comp $5=P$ solo $10 \mathrm{~m} / 10 \mathrm{~cm}$ e comp.6 $=P$ solo $5 \mathrm{~m} / 20 \mathrm{~cm}$ ) 


\section{CONCLUSÕES}

A espécie Cecropiapalmata se mostrou um importante componente em paisagens amazônicas como os agro-ecossistemas familiares no Baixo Amazonas, haja vista os altos teores de fósforo acumulados em seus tecidos foliares e, portanto com alto potencial como um dos ingredientes em tortas ou utilizadas como mulch em Sistemas Agro-florestais e Capoeiras enriquecidas. Além disso, os solos sob influência da rizosfera desta espécie apresentam importante hot spots de fósforo em ambientes edáficos com estresse de fósforo como os latossolos amazônicos. A expansão da prática de preservação desta espécie pode delinear modelos de transição agro-ecológico importantes no contexto da agricultura familiar em Assentamentos Rurais na Amazônia.

\section{REFERENCIAS BIBLIOGRÁFICAS}

1. CAMPOS, E. H; Alves, R.; Serato, D. S.; GelzeSerrat de Souza, G. S.Acúmulo de serrapilheira em fragmentos de mata mesofíticae cerrado stricto senso em Uberlândia-MG. Soc. nat. (Online), Jun 2008, vol.20, no.1, p.189-203.

2. FERREIRA, S.D. Composição Florística de Florestas secundárias e implicações da tecnologia de corte- trituração e mulch sobre a serrapilheira em agroecossistemas locais. Trabalho de conclusão de curso (Graduação). Universidade Federal do Pará. 2007.

3. HERNADEZ, F.P. et al. Final report on the forest inventary project at the Tapajós National Forest.São José dos Campos, SP, Brasil: Instituto Nacional de Pesquisas Espaciais. INPE. 126. 1993

4. JULIO, C. Determinação de fósforo em material vegetal. Universidade Federal Rural da Amazônia. 2004.

5. OLIVEIRA, P.C. Características ecofisiológicas de espécies potencialmente acumuladoras de fósforo em florestas secundárias no Nordeste Paraense, Tese de Doutorado, UFRA, Belém. 2005.

6. RIGOBELO,E. C.e NAHAS, Ely Seasonal fluctuations of bacterial population and microbial activity in soils cultivated with eucalyptus and pinus. Sci. agric. (Piracicaba, Braz.), Feb 2004, vol.61, no.1, p.88-93. 